\title{
Meeting the Needs of Mothers and Families? Family Self-Sufficiency Programs and Goals of Homeownership
}

\author{
Sharon Lindhorst Everhardt, $\mathrm{PhD}$ \\ Troy University
}

* Please address correspondence to Dr. Sharon Lindhorst Everhardt, College of Arts and Sciences, Troy University, 136 Catoma St., Room 105, Montgomery, AL 36103. E-mail: severhardt@ troy.edu.

\begin{abstract}
This phenomenological study examines the complex barriers faced by low income women of color and their families in their attempts to achieve self-sufficiency and/or homeownership. The study sample included 24 low income women of color who participated in a Family Self-Sufficiency Program in a Midwestern state. This article focuses on six narratives as illustrations of patterns found in the complete sample. Barriers identified by the participants include employment, education, savings, and transportation. This study begins to address gaps in existing literature on the journeys that low income women and their families engage in on their paths toward economic self-sufficiency. Many have an active goal of homeownership as well, but the pathways to that goal are complicated by women's multiple and intersecting social locations, as well as the barriers mentioned above.
\end{abstract}

Keywords: low income, women of color, families, economic self-sufficiency, homeownership

The theoretical and conceptual connections between homeownership and economic self-sufficiency are complicated. Generally, families are able to become homeowners because they are economically self-sufficient (Shlay, 1994).

Economic self-sufficiency is typically defined as economic independence from government or family assistance (Shlay, 1994). An important goal of this study was to uncover what being "economically self-sufficient" means to these low income women. This study also attempted to determine whether or not women consider homeownership to be an important part of economic self-sufficiency. Family Self-Sufficiency (FSS) programs are designed to help low income families reach their self-sufficiency goals, including homeownership (Rohe \& Watson, 2007). It is therefore important to examine low income families' experiences 
while enrolled in these programs because programs such as these may be their only chance for economic independence and a better quality of life.

For low income families, homeownership may be the catalyst for achieving economic independence over the long term (Shlay, 1994; Rohe \& Watson, 2007). Promoting homeownership as a tool for economic independence is not new; homeownership has been central in housing policy since the Great Depression (Shlay, 1994). Homeownership is one of the most commonly discussed goals associated with achieving the American Dream (Shlay, 1994; Rohe and Watson, 2007). This may explain why the U.S. Census Bureau reports that the majority of Americans (68.2 \%) owned homes in 2007 (U.S. Bureau of the Census, 2007). It should come as no surprise, then, that many low income families are striving for the same dreams of economic independence as other Americans - not only the opportunity to be economically independent but also to purchase their own homes.

However, the pursuit of economic self-sufficiency and homeownership for low income women of color and their families is complicated by the presence of personal- and system-level barriers which operate simultaneously (Lindhorst Everhardt, 2009). Existing literature (e.g., Edin \& Lein, 1997; Ehrenreich, 2001) has focused on women's personal, organizational, and societal barriers separately rather than how women's personal- and system-level barriers intersect with one another making barriers more difficult for women to overcome. Although personal-level barriers should be viewed separately from system-level barriers, both are equally important in explaining the hardships that low income women and their families experience in striving for economic self-sufficiency and/or homeownership. This study used data from 24 in-depth interviews to better understand what barriers low income women and their families face as they attempt to reach economic self-sufficiency, as well as whether homeownership was one of their economic self-sufficiency goals, and how they experienced being part of a FSS program. Six of the 24 narratives are discussed in detail in this article, and these narratives provide a window into the lives of low-income mothers in my sample.

Intersectionality is the conceptual framework for this study and data analysis followed phenomenological methods of inquiry (Creswell, 1998). Intersectionality is used not only as a theoretical framework in this study, but also as an analytical tool by which the interconnectedness of barriers and social locations are examined. Intersectionality theory argues that the effects and experiences of gender, race, class and other categorical differences cannot be understood separately from one another; each of these categories shape people's experiences and life outcomes (Weber, 2001; Davis, 2008). Intersectionality theory was originally coined by Kimberlé Crenshaw (1989) to encourage feminist and anti-racist scholars to recognize all women's experiences and not simply those of white, middle class women (Simien, 2007; Davis, 2008). In other words, scholars must recognize that women experience life in varying ways because of their multiple social locations and social contexts. What is a privilege for some women and their families could be oppressive and a liability for another (Hill Collins, 1990; Davis, 2008; Denis, 2008). 
While many people may agree that homeownership is a privilege and an asset to build upon, it can also be oppressive and a liability for others. The Consumer Federation of America (CFA) found women at all income levels are still more likely to receive sub-prime home mortgages than men, making it more difficult for them to accumulate wealth through homeownership (Heavens, 2006). Therefore, while homeownership is often thought of as a measure of selfsufficiency and a positive step toward building wealth through equity, not everyone benefits from homeownership in similar ways. This seems to be especially true for single women of color who have the highest incidence of receiving sub-prime lending. Sub-prime lending comes with high interest rates that often extract any equity built in a home through high mortgage payments. Since single women only have one paycheck to depend on, this puts them at risk when unexpected repairs to their home or car occur or unanticipated bills must be paid. While homeownership likely benefits some women, such as white married women, it can be a liability for single women of color. Intersectionality tells us that we cannot ignore class, gender, race, or marital status as an intersecting identifier that may affect a woman's experience in obtaining loan. Other social locations, such as educational background and disability status matter as well.

These examples illustrate some of the main arguments that intersectionality theory makes. It demonstrates that the social context is important in analyzing the lives of women as it allows us to see that the experiences of women are not all the same. Homeownership is a privilege for some women and a liability for others. Clearly, institutional discrimination and personal bias and prejudice on the part of mortgage lenders greatly contributes to women's varied experiences in attempting to become homeowners or actually being one.

The guiding research questions for this study are:

(1) What barriers do low income women and their families face in their attempt to reach their economic self-sufficiency goals?

(2) Is homeownership a goal for low income women and their families? These questions are designed to fill some of the gaps in existing qualitative literature on low income women and their families with regard to economic selfsufficiency and homeownership. These research questions also reflect the goals of a much larger project, from which the data for this article are drawn. Like the fuller study, this article focuses on specific barriers that women in the study discussed, and how those barriers shape economic self-sufficiency and homeownership goals.

\section{Literature Review}

In 2013, approximately $65 \%$ of American families owned their homes (Arnold, 2012; Bloomberg News, 2013). In recent years, mortgage rates have remained low (averaging under 5\%), housing prices are rising, foreclosures are declining and the overall climate of the housing market seems to be slowly improving (Coates, 2013). Unfortunately the housing market is not a sole predictor of who obtains homeownership in the U.S., however. Family structure, marital status, and gender, for instance, weigh heavily on one's ability to become a homeowner. 


\section{Family Status and Homeownership}

It is important to examine family structure when examining the profile of homeowners in the United States. Overall, married couple households have higher homeownership rates than non-married single person households (U.S.

Department of Housing and Urban Development, 2001; Garriga et al., 2006; U.S. Bureau of the Census, 2013). For families headed by a single person, females had a higher rate of homeownership than did males from 1995 to 2012.

The number of non-married women in the U.S. has increased along with the number of women who are both heads of households and single parents (Martin, 2010). Women's greater emphasis on homeownership may be partially explained by the culturally defined responsibility of primary parenthood and as stability providers for their children. In other words, women and men may have different priorities and preferences for housing and homeownership based upon their gendered life experiences and attitudes toward parenting and families (Blaauboer, 2010).

Nonetheless, the presence of children also has been found to be significant when examining one's likelihood of achieving homeownership (Haurin, 2013). A general pattern documented by many housing studies is that homeownership rates are higher among households without children than households with children (U.S. Department of Housing and Urban Development, 2001). Although it is clear that single mothers are making advancements in their rates of homeownership, they still lag behind many other family structure groups.

\section{Federal Programs for Self-Sufficiency and Homeownership}

Self-sufficiency as a term surfaced only after the passage of the Personal Responsibility and Work Opportunity Reconciliation Act (PRWORA) (Pinsoneault, 2006). Self-sufficiency became a significant focus given its goal of moving people from governmental dependence to economic independence (Santiago \& Galster, 2003). Homeownership may be the greatest example of selfsufficiency as well as the best illustration of its challenges (Bogdon, 1999; Rohe $\&$ Watson, 2007). As a result, HUD developed the Family Self-Sufficiency (FSS) program.

The aim of this program was to assist families in subsidized housing in reducing their dependence on public assistance and in gaining economic independence (Bogdon, 1999). The FSS program may provide the following: individual action plans for participants through case management; help in obtaining employment and further education, child care and transportation arrangements; parenting classes; substance abuse counseling; and economic incentives that promote self-sufficiency (Bogdon, 1999).

The main incentives for families to participate in the FSS program are the escrow account and supportive service network, of which they become a part of when they enter the program (Ficke \& Piesse, 2004). The TMHA Escrow program is intended to aid FSS participants by reserving any rent increases due to an increase in a participant's income in an escrow account for the participant's future use. An escrow account gives families an opportunity to save money, 
which they may not otherwise have the opportunity to do without this program. To complete the FSS program successfully, a family must maintain employment and no longer receive cash benefits, such as Temporary Assistance for Needy Families (TANF), at the time they receive escrow payments. Escrow payments may be used for any economic goal such as paying for college tuition or for a down payment to purchase a home. Supportive services such as child care and transportation are critical for the success of many participants as these are often barriers to being able to work or obtain education. Thus, the major objective for this program is to get people off of public assistance for the long term by helping them gain the tools to be economically independent.

Although many qualitative studies discuss economic self-sufficiency as a goal, there is a dearth of qualitative studies concerned with women's experiences of homeownership. As a result, there is a specific need for researchers to examine women's experiences of homeownership as a measure of economic selfsufficiency using theme-seeking, qualitative methodologies. The barriers single women in particular face in overcoming economic obstacles need to be addressed from the perspectives of the women who live these realities and need to include housing contexts, since economic hardships involve more than just barriers to good jobs or cash assistance. In addition, if a FSS program provides resources and creates a best case scenario of help for low income women, more study of individuals in these programs is needed. It is critical to investigate women's experiences while enrolled in FSS programs and how the intersections of multiple and intersecting social locations (such as race, class, gender, employment status, education, the presence of children, marital status, disability status, and availability of transportation) shape their perspective on the program and their experiences of being part of it. FSS programs and the assistance they provide may constitute the only real hope women have of achieving any measure of economic self-sufficiency, yet may not address enough barriers and contexts to increase single women's rates of homeownership in any meaningful way.

\section{Methods}

This project uses a qualitative design for inquiry because most of the research that addresses women, economic self-sufficiency or homeownership has utilized quantitative methodologies, which do not allow us to hear the full voices of women and their families. A qualitative, phenomenological approach was best for this study because its purpose was to "describe the meaning of the lived experiences for several individuals about a concept or the phenomenon" (Creswell, 1998, p.51; see also Seccombe et al., 1998).

Using this method of inquiry, I looked for the "essential, invariant structure or essence" of low income women's lived experiences (Creswell, 1998). In other words, this study searched for the single underlying structure that united women's experiences in their attempts to achieve economic self-sufficiency. An example of an underlying structure or commonality in this study is women's reports of economic struggle and poverty. In the search for a greater understanding of these women's experiences, as Husserl states, it was important to "suspend all judgments about what is real- the "natural attitude"- until they are 
founded on a more certain basis (Creswell, 1998, p.52). Therefore, I attempted to identify and bracket any perceived ideas or biases, both before and after making contact with participants.

\section{Recruitment}

Selection and recruitment of participants for this study took place in 2008. Access to FSS program participants was gained through a local housing authority--Truetown Metropolitan Housing Authority (TMHA) ${ }^{i}$, which promoted the goals of self-sufficiency and homeownership programs to its low income residents. To help participants become economically self-sufficient, TMHA provides employment and training opportunities, educational programs, homeownership, and financial management classes, escrow savings and individual development accounts and linkages to other community services (Lindhorst Everhardt, 2009). However, TMHA does not provide childcare or transportation for participants. Approximately $73 \%$ of households waiting to receive housing assistance from TMHA have children. The Public Housing Family Self-Sufficiency (PH-FSS) program, from which participants for this study were selected, reported that participants were $21 \%$ male and $79 \%$ female at the time of the study. PH-FSS participants' racial-ethnic backgrounds were 83\% African American, 8\% White, $7 \%$ Hispanic/Latino, and 2\% "Other" in 2008. Low income is defined as those who possess $0-30 \%$ of the study area's 2007 median income of \$35,216 (Parker \& Messina, 2008); TMHA serves Truetown residents with incomes in this particular range.

The participants for this study were selected using criterion sampling. The eligibility criteria for participation in TMHA's PH-FSS program are (1) having a low income and (2) the desire to make efforts toward achieving self-sufficiency. Using these same criteria, a list of 88 potential participants was generated from TMHA's FSS participant list. Recruitment letters explaining the study were sent to 88 potential participants on agency letterhead. The response rate was approximately $34 \%$. The low response rate is most likely explained by some of the same barriers this study found to inhibit the research participants' abilities to achieve their self-sufficiency goals. Gillis et al. (2001) explains that many factors affect response rates such as: 1) overcoming fear and mistrust, 2) lack of transportation, 3) lack of childcare, 4) health problems, 5) history of being ignored, and 6) lack of time. Nonetheless, enough women were recruited to secure data saturation. At the suggestion of TMHA administrators, participants were offered a $\$ 30$ retailer gift card as an incentive, and this incentive definitely helped with recruitment. The final sample included 24 low income women who were part of the PH-FSS program (see sample description below).

\section{Data Collection}

Data collection was carried out through a one-time, in-depth interview with each of the 24 low income women. Participants also completed a brief demographic survey after the interview. During the interview, participants were asked questions about their financial assets, number of children, age, marital 
status, residential history, employment, history of and interest in homeownership, health status, future goals, and experiences with the FSS program.

All interview tapes and field notes were reviewed during and directly after data collection. Each statement was treated equally, and a list of non-repetitive, non-overlapping themes was created (Creswell, 1998). Key themes already defined by the interview guide, such as "barriers," "self-sufficiency," and "homeownership," were analyzed in addition to new themes and key words that arose directly from the data. I developed overall descriptions of each woman's lived experiences, and similarities and differences among their perceptions and experiences were highlighted, especially those from different social locations (race, marital status, age, number of children, disability status).

\section{Sample}

The full sample includes 15 single women, three married women, three women in cohabiting partnerships, two divorced women, and one widowed woman. A total of 20 women in the study were African American, three women were self-reportedly bi-racial, and one was Hispanic American. Of the 24 women, 18 were mothers, nine had three or more children, six had two children, and three had only one child. Out of the 18 women who were mothers, seven had children under the age of five. Only nine out of the 24 women owned cars, and 12 reported to be employed at least on a part-time basis.

Narratives from six of the 24 women were subsampled for case-level analysis in this article, although at times I also refer to data collected on the full sample to broaden the analysis. The narratives chosen were the most descriptive of the phenomena being studied, based on systematic first-and second-stage theme building. The commonalities among the six narratives were that all of these participants were: (1) mothers, (2) seeking homeownership, (3) actively enrolled in the FSS program, and (4) demonstrating a range of personal-and system-level barriers. Major differences among these six narratives include: (1) number of children, (2) marital status, (3) enrollment (or lack thereof) in savings incentive programs, (4) employment status, and (5) access to reliable transportation.

\section{Findings and Discussion}

The findings discussed here are organized by the barriers to economic self-sufficiency and homeownership that low income women and their families reported. The primary barriers discussed include: employment, education, savings, and transportation. This section also discusses how these barriers are always interconnected. The findings under each barrier are illustrated by women's narratives to demonstrate how these specific barriers impact the lives of the low income women and their families. As this article highlights, achieving economic self-sufficiency is a complicated process for those who aim to achieve it.

\section{Full Sample}

Many of the most common barriers to self-sufficiency and homeownership for the women in this study were related to employment. Sixteen of the 24 women 
participants cited unemployment, job instability, and/or underemployment as a barrier to achieving economic self-sufficiency and/or homeownership goals. Unemployment, job instability, or underemployment are especially of concern in the case of purchasing a home, since mortgage lenders require proof of steady income before they allow individuals to obtain a loan. One's income and job stability has a profound impact on whether or not one will qualify for a mortgage and how much money one is allowed to borrow when purchasing a home.

Joblessness in particular can be an almost insurmountable obstacle when trying to meet self-sufficiency goals through homeownership.

In addition, 12 out of the 24 women who participated in this study said that their current education level was a barrier to achieving their self-sufficiency goals. Education can be a barrier to self-sufficiency for many low income women and their families because they do not have the credentials necessary to qualify for better-paying jobs, access to mentors who may assist them in meeting their goals, and access to social networks that may provide better life opportunities in the way of training, employment and support.

All 24 women participants in this study (and TMHA administrators interviewed separately for the larger study) acknowledged that having little to no savings coupled with a low income made it difficult to progress toward selfsufficiency. Yet, all 18 participants who mentioned lack of savings and low income as barriers had the goal of becoming homeowners.

Overall, 15 out of the 24 women in this study reported not owning their own vehicle. Although city buses provide services for local residents, the local bus system recently cut approximately 20 routes to save on operating costs during the current economic crisis. The local transit system is perceived as an unreliable transportation option method as a result. Lack of transportation can be a barrier for low income women because it can severely limit their opportunities for stable employment and education; both are necessities for the achievement of economic self-sufficiency and homeownership. Lack of access to transportation is a barrier that is therefore interconnected with educational and employment barriers. Without reliable transportation, the prospects of securing educational or employment opportunities are difficult.

\section{Narratives}

The six narratives presented here were subsampled to illustrate on a caselevel the larger findings of this study. These cases further highlight employment, education, savings, and transportation as intersecting barriers. Women in this study felt that overcoming these particular barriers would make a difference in helping them achieve their goals of economic self-sufficiency and homeownership. In the following sections, specific cases are used to illustrate individual, yet interconnected, barriers.

\section{Employment: Molly and Agnes}

Molly, a single, 28-year-old, African American participant with one child who was employed part-time as a cashier, described her employment as a barrier to being able to return to school and purchase her own home. She stated, "I have 
always worked dead end jobs and don't make enough money. My goal is to get a decent job. A job where I could take care of my baby, pay bills, and have some savings. I can find a house to buy that I can afford, but I need a good job to clean up my credit." Molly described her job experience and why she continued to be a TMHA resident, despite her employed status. Molly was employed as a cashier earning $\$ 8.00$ per hour, but recently had her hours cut from 40 to 27 by her manager. As a result, Molly went from being a full-time employee to a part-time employee with a $\$ 104.00$ weekly pay reduction. In other words, Molly was earning $\$ 320.00$ per week and was reduced to a weekly income of $\$ 216.00$ before taxes, after her hours were cut.

Despite this recent increase in hardship, Molly's self-sufficiency goals still included earning a college degree and becoming a homeowner. Returning to college was her immediate goal; homeownership was more of a long term goal. Molly needed a stable job and a higher income in order to be able to pay off debts and return to the local community college, however. Molly was informed that she must repay a $\$ 1,500.00$ debt plus interest to the local community college, before she would be able to return as a student. Making $\$ 8.00$ per hour on a part-time basis while caring for a young child did not allow much flexibility for how she allocates or spends her money. Clearly, Molly's job instability impeded her ability to meet either of her goals. It is evident that participation in just any job does not automatically allow for economic independence and new life advantages.

Agnes, a married, 31-year-old African American participant with two children, described her experience of searching for work after completing a dental assistant program:

"I am part of the American Dental Association. They're a member of the local dental society, which holds my application and my resume and circulates it around to doctors in this city that may have a call off. So they will go through their computer and say, 'Ok, there's an assistant, she's available at these times and on these days,' and then they will call me. But, it's like, I am trying to get with a doctor full-time and basically it's just hard because they're full. You know, most assistants have been at their jobs a long time."

Upon successfully completing her dental assistant program, Agnes joined organizations affiliated with the dental profession such as the American Dental Association in hopes of networking with a dentist who needed to hire a dental assistant. The local dental society in Truetown helps graduates find temporary and permanent, part-time and full-time positions. However, the society had only been able to place her in a few one-day assignments with local dentists at the time of her interview. Agnes' ultimate goal was to find permanent, full-time employment with a local dentist, not another temporary assignment. She expressed her frustration with this job search. Agnes's self-sufficiency goals included both fulltime employment and homeownership. She had recently completed homeownership classes and knew stable employment and income were her main barriers. Despite trying to do everything right, Agnes's unemployment remained the most immediate barrier. 
The narratives of Molly and Agnes echo general findings from the full sample. As the current qualitative literature argues, many women benefit from participation in the workforce, especially those who are skilled in a trade or hold college degrees (Pierre, 2007). Nonetheless, women are unable to gain economic independence and advantage from employment alone. Molly's situation of unstable part-time work clearly illustrates this point. Women like Molly often have to seek government aid to get by and, therefore, remain economically nonself-sufficient.

Molly's situation also illustrates how personal level barriers intersect with system level barriers. Molly owed a local college $\$ 1,500.00$, and was told that it must be repaid with interest before she would be allowed to return to school. Although having debt is considered to be a personal level barrier, the inflexibility of the college's policies and practices regarding her debt blocked Molly from continuing down the path towards self-sufficiency. As a result, Molly felt powerless because she did not make enough money to support herself and her child, let alone to pay off her tuition bill. While the lack of a steady, well-paying job was the primary barrier in this case, Molly's situation was fraught with other economic and non-economic barriers, such as a low level of education, childcare, having a lack of savings, and holding debt.

The similarities and differences between Molly and Agnes are relevant when trying to understand the challenges that low income women face in striving for economic self-sufficiency and/or homeownership. Both women stated that homeownership was one of their economic self-sufficiency goals. Full-time work was really what both of these women needed to achieve any measure of selfsufficiency, yet both were blocked from this in some way. Both also identified as low income, African American mothers. However, there were some major differences between these women as well. At the time of the study, Molly was employed whereas Agnes was unemployed yet actively looking for full-time work. It is difficult to determine which of these women were closer to obtaining full-time employment because of their additional barriers, however. Agnes completed dental assistant training and was poised for full-time work, but reported difficulty finding work. Molly had not completed her postsecondary education, but was employed part-time. In the long term, Agnes may be better off financially than Molly because of her education, which could mean higher income and better employment prospects long-term, but both were suffering financially at the time of interview. Agnes was also married, which may have provided an additional safety net at times (if her partner was employed), but research has also showed that marriage can decrease the amount of aid available and can act as a drain on resources if a partner is unemployed (Edin \& Lein, 1997). Thus, marriage is not necessarily a direct economic benefit and it is unclear whether it was to Agnes at the time of the study. Nonetheless, it seems that Agnes' partner supported her pursuit of education and training, which may have allowed her to finish her dental assistant program. Thus, emotional support from marriage may better position Agnes in the long run, even if it does not help her lessen her more immediate employment problems. 


\section{Education: Mabel and Shannon}

Mabel, a single, 34-year-old, African American participant with four children who worked part-time as a nurse's aide, described her education level as a barrier to earn more income and, ultimately, purchase a home. She stated, "I want to be a LPN instead of a nurse's aide. My salary would triple. If I had my LPN license, I would just buy me a house." Mabel described her desire to climbs the ranks of the nursing profession by obtaining more education and qualifying for a Licensed Practical Nurse (LPN) license. The LPN license would allow her to move out of her position as a State-tested Nurse's Aide and access additional income. Mabel explained that her part-time status and low wages meant homeownership was not within her reach at the time of her interview. She wanted to work full-time but found it too difficult to do so while being a single mother of four children. Her solution was to attempt to gain more education first. She felt that a LPN position could allow her to earn more money without having to work a full-time job until her children were older. Education was not only a solution to her economic problems, then; it was also, indirectly, a solution for her childcare problems.

Mabel's assumption that additional education - and, eventually, a better paying job - will lead to homeownership may be correct. Molly, Agnes and Mabel all discussed education and additional income as twin requirements for achieving self-sufficiency. Education is typically a requirement for receiving a "good" job -a job that pays a worker a steady enough income for him or her to have a comfortable and stable life as a homeowner, with food in the refrigerator, a car in the driveway, and children's needs being met. Nevertheless, as Agnes' case shows us, education does not guarantee these resources/outcomes. Furthermore, it was unclear at time of interview whether Mabel would be able to secure the education necessary for her to secure a LPN license. Financial problems and childcare problems made going back to school difficult for Mabel. Despite the fact that women in this study saw some barriers as primary and defined others as secondary, it is clear that multiple barriers intertwine to make any one barrier hard to achieve.

Shannon, a single, 42 year-old, African-American mother of five who was employed full-time as a nurse's aide, similarly discussed her desire to obtain more education. She also explained the difficulties in securing this education, however.

"Actually, I just got tired going back to be an RN. I got discouraged because of the math classes. The math has always been a little tough for me. To graduate from high school, I had to go to night school for the math. It has always been a struggle for me. I am not one to give up. But I have come to terms with the fact that I am not good at math. So I decided to change majors because I really did not want to be a LPN. I wanted to be an RN. I got tired of going back to school and flunking that math. You know, then you are on academic probation and you got to write a letter. I have been able to start my NODA account and attend classes about my finances. I joined the Homeownership program and make major accomplishments with regards to my credit. I have had pay increases and bonuses. I always wanted my own home. But I think a college degree 
would be helpful for my employment situation and becoming a homeowner."

Shannon dropped out of the Registered Nurse (RN) program and decided to change her major to Criminal Justice because she had an interest in the area and it did not require as much math to receive a degree. Shannon expressed her desire to get a bachelor's degree so that she can earn more money to provide more for her children and become a stable homeowner. She explained during her interview that she has taken the steps towards being knowledgeable about becoming a homeowner by joining the homeownership program and taking finance classes. She has cleaned up her credit and saved money for a down payment through the NODA escrow program. It seemed as if Shannon was doing everything right on the path towards homeownership.

Shannon expressed few reservations about being a mom, worker, and student and did not talk as much as others about those statuses being barriers to self-sufficiency. Although Shannon was busy multi-tasking as a mother of five, a full-time worker, and a full-time student, she was still progressing toward her selfsufficiency goals because she had a familial support structure in place. Shannon's extended family was very supportive and helpful, and she benefitted from this safety net of economic resources and childcare. The presence of this support structure ultimately lessened the overall effects of the barriers Shannon faced, making her somewhat different from other interviewees. While she still faced considerable barriers, it was easier to see how additional education might be the remaining goal for Shannon to achieve before accessing better employment and homeownership.

\section{Savings: Makenzie}

Makenzie, a single, 28-year-old, African American participant with two children who was employed part-time as a case manager and a full-time student, described her primary barriers to achieving her goal of homeownership. She stated, "For the homeownership thing, I would have to say savings. I don't have enough money saved up." What was not stated in this quote is how complicated Makenzie's situation is, however. Makenzie needed a child care that had extended hours to accommodate her hectic life as a mother, renter, worker, and student. The fact that she had no family living nearby and had been unable to locate a child care facility that was open past $6 \mathrm{pm}$, limited her ability to earn money. Further, Makenzie had a criminal record, making her options for employment limited, at least from her perspective. As a result, she had fully committed herself to obtaining higher education in an attempt to counter some of the stigma associated with having this criminal record. Makenzie talked about savings as a barrier to homeownership because she believed a down payment would be required for her to purchase a home, yet Makenzie was not enrolled in TMHA's savings incentive program and had several other interconnected barriers to worry about more immediately than savings. Still, in thinking ahead to possible homeownership, Makenzie cited savings as her major barrier.

Shannon was the only woman in the cases presented here who was enrolled in TMHA's savings incentive program. For Shannon, being part of a 
savings incentive program in conjunction with full-time employment and a supportive network seemed to have an impact on her ability to save and support her family financially. The women without savings activity in this study illustrate another point where personal- and system-level barriers intersect. Although the inability to save money can be viewed as a personal-level barrier, it can also be a system-level barrier because of the entry requirements some saving incentive programs place on potential participants. The TMHA savings incentive program available to women in this study required women to first increase their earnings, so that the additional income could be placed in their escrow account. For Makenzie, Molly, Mabel, Agnes, and Lucinda ${ }^{\mathrm{ii}}$, lack of savings was a real barrier. Current literature suggests that for lower income, single women (especially women of color) and their families, goals of self-sufficiency via homeownership are especially threatened by a lack of savings (Collins, 2002; Engle, 2013). From an intersectionality perspective, women's efforts to save money for a home may also be threatened by the lack of a support structure and exact nature of their employment situation. Shannon was better off than others in the sample (and closer to her goals of homeownership and self-sufficiency) because of savings, which was bolstered by familial support and full-time employment. Agnes may also be better able to save in the long term than Molly, Mabel or Makenzie, if she can secure full-time employment, since she is already certified as a dental assistant and has a partner's support at times.

\section{Transportation: Lucinda}

In addition to reporting economic, educational and employment barriers to self-sufficiency and homeownership, some low income women in the full sample and in the narratives also reported transportation as a major obstacle. Existing studies (Edin \& Lein, 1997; Lichtenwalter et al, 2006) of low income women and economic self-sufficiency provide evidence of low income women's claims that lack of transportation can severely hinder their ability to advance toward economic independence. Transportation as a barrier was especially relevant to this group of low income women because most lived in inner-city areas of Truetown, where job opportunities were scarce and public transit was limited to bus transportation or taxis. Like many other cities in the U.S., the most attractive job opportunities were found on the outskirts of town or in the suburbs of Truetown, making ownership of one's own vehicle almost imperative for economic survival. Wilson (1996) confirms these trends by arguing that people who live in the innercities are disadvantaged by the lack of job opportunities available in their areas. Job opportunities in these areas have diminished with the decline of the manufacturing sector and employers opting to move out of the inner-cities and into the suburbs (Wilson, 1996).

Lucinda, a single, 40-year-old, African American mother of two who was disabled explained how a lack of reliable transportation complicated her life.

"I rely on my grandmother to take me places and that is not working out. I walk up to Kroger, but I cannot do a real grocery shopping trip. I like to go to the meat store. I do not like to waste my little bit of food stamps on 
overpriced items at Kroger. I would take [the bus] if it was not 60 minutes away. They do not have regular bus routes out here."

Unlike many other participants in this study, Lucinda lived in a township a good distance away from the central city of Truetown. As a result, Lucinda's options for transportation were quite limited since she did not own a car and the closest access point for the bus was an hour away on foot. In contrast, some of the other women in this study had the option to utilize the bus system, had their own cars, or had access to family cars. Lucinda expressed frustration about not having her own transportation because having an infant and only being able to rely on her grandmother or her own two feet made her life hard. She could never do a large grocery shopping trip because she had to carry the groceries home and also be able to push her son's stroller. Lucinda's lack of transportation often limited her to an overpriced selection of food at the grocery store as well. At the time of her interview, Lucinda was receiving food stamps and felt she needed to stretch them as far as they would go which, in her mind, meant shopping in stores other than Kroger foods. When asked why she did not take the bus, she explained to me that the bus was simply too far away to gain access to, especially with an infant and/or in poor weather conditions.

Lucinda also revealed that her relationship with her grandmother was strained and she felt controlled by her grandmother. She explained how she wanted to get her General Education Development (GED) credential, but it has never worked out. When asked why it has never worked out, she explained that she had to rely on her grandmother to take her to the GED classes and sometimes her grandmother was unwilling, or sometimes they argue and then Lucinda does not go. Lucinda expressed a real desire to want to be independent from her grandmother but felt trapped because of her dependence on her grandmother for transportation. Lucinda expressed the desire to become economically independent so that noone (e.g., her grandmother or caseworker) would meddle in her affairs or ask her questions about her life. Lucinda was partially disabled as well, yet she still had the ability to work part-time. She had been unable to find a job in recent months, though, because of her low educational level. If she had a reliable and consistent form of transportation, then she could have finished her GED classes, taken the GED exam, and, hopefully, gained stable part-time employment.

Securing part-time work was a critical goal for Lucinda because she needed to earn an income to be able to advance in the local FSS program and escrow any increased earnings beyond her disability check. Despite this, however, Lucinda's primary barrier was reportedly transportation. While Lucinda talked primarily about transportation, it is clear from her conversations that she faced a multitude of interconnected barriers that are difficult to separate. Her ultimate goal was to relocate to another state to be with other family members, to get away from her current family and geographical limitations and start fresh. Unlike Molly, Agnes, Mabel and Shannon, Lucinda was disabled, arguably making all the other barriers she faced like transportation, education, income and lack of a supportive family network worse. The transportation barrier also may have been especially poignant for Lucinda because of her personal difficulties with physical mobility. Lucinda would first need her transportation barrier 
removed to begin to address her educational barrier, and then her income barrier in order to progress toward her self-sufficiency goals. But, all of these barriers would have to be dealt with in order for Lucinda to have any chance of selfsufficiency or homeownership. Lucinda knew the weight of these intersecting barriers and talked about homeownership as desirable, but not realistic for her and her family in the near future. Lucinda's narrative reminds us that, although all of these women share commonalities in the barriers they face to economic selfsufficiency, the nature and weight of the barriers change for each individual, depending on their exact personal and social contexts.

There are many similarities and differences in the lived realities of Molly, Agnes, Mabel, Shannon, Makenzie, and Lucinda. All of these women were African American women raising children under the age of 18. Molly, Agnes, Mabel, Shannon, and Makenzie cited homeownership as one of their selfsufficiency goals. A difference among these women was their employment status. Molly, Mabel and Makenzie worked part-time. Agnes had only been able secure temporary work, and Lucinda was disabled and unable to find the part-time work she could handle. Shannon worked full-time and, as a result, had higher earnings. Shannon saw homeownership as a very real and obtainable goal for her and her family in the near future, whereas Molly, Mabel, Agnes, Makenzie and Lucinda generally discussed homeownership as a dream that will someday come true for them and their families. Lucinda went so far as to say that homeownership was not really feasible for her, because of her inability to secure education and employment.

Educational backgrounds and aspirations also made these six women vary. Makenzie was in the process of attending college full-time. Like Makenzie, Shannon wanted an additional degree to feel more economically secure as a homeowner, and to be able to explore other job opportunities. On the other hand, Lucinda expressed reservations about enrolling in school (or even finishing her GED) because her home situation was unsupportive and complicated, and Molly saw returning to school as unrealistic because of her debt to the local community college. Agnes had recently completed dental assistant training and felt secure in her education and training, but still struggled to find permanent, full-time work. Thus, Makenzie and Shannon may have the best chances of achieving economic self-sufficiency and homeownership goals if education represents a primary barrier. As Agnes's case has demonstrated, however, investment in education can be a gamble in a tough job market, especially for low-income women.

Another difference between these participants was marital status: Agnes was married with children whereas Molly, Mabel, Shannon, Makenzie, and Lucinda were single mothers. This difference in marital status was significant because reliance on a sole income makes it harder to break the cycle of poverty and reach self-sufficiency goals. On the surface, one might assume Agnes may be more likely to reach her goals of becoming a homeowner because she is married. However, Agnes did not discuss her spouse's income. It is not safe to assume in Agnes' case that she was any closer to becoming a homeowner than the single mothers in this study because of her marital status. 
Although job instability and education have been well-documented as important barriers to self-sufficiency, existing studies fail to show how these barriers operate both at the personal and system level, and how barriers can also intersect with one another at both levels. That is, intersecting barriers vary in their effects on different women so that educational and employment barriers are not experienced in the same way by all low income women. Women with the least amount of education and family support in this study reported the most difficulty securing any job, whereas others with some education and some family support reported only having difficulty securing full-time work or high-paying work. Obtaining more education is not always a guarantee to better employment, as Agnes's case demonstrates, but, if she can secure work then she will automatically be better off than others in the sample because of her certification. Thus, spending money on education can be a gamble for low income women at times. Some interviewees report they must limit the jobs they take because of health problems or disability, the scarcity of affordable or timely childcare, and a lack of transportation. Women like Molly, Mabel, and Lucinda, who have multiple and intertwined barriers, appear to struggle the most in securing any measure of self-sufficiency. The complex intersection of barriers to selfsufficiency, including homeownership, is clear for the women in this study.

\section{Supportive Networks for Low Income Women}

The women's cases presented here illustrate the important differences family members can make in the lives of their loved ones. Being a single mother can amplify instability outcomes and problems in gaining more education, income and savings. What appears to make a difference in low income mothers' lives and the lives of their families, however, is having a supportive network around them, as Shannon's case demonstrates. Obtaining an educational degree can be difficult for single mothers as it requires additional resources like income (as in the case of Molly) and adequate childcare (as demonstrated in Mabel's case). Further, adequate childcare often requires additional income that single mothers like Mabel and Makenzie do not have. Yet, Shannon and Agnes demonstrate that when mothers have the right balance of familial or community support and economic resources, they are able to progress toward their goals. For Agnes, her ability to complete her educational training could be because she is married, and that relationship status may allow her access to more support and childcare options; we do not know for certain. Shannon's success in securing full-time employment despite being a single mother was facilitated by a strong familial support network, and that network has made the difference for her in bringing her closer to her goal of obtaining self-sufficiency and homeownership. Shannon's situation is completely different from the situations of Molly, Mabel, Makenzie and Lucinda who are also single mothers - specifically because of the support she has.

\section{Conclusion}

All 24 women who were part of this study indicated economic selfsufficiency and homeownership as goals, but the women demonstrated variability 
with regard to how close or how far away they were from reaching them, particularly the goal of homeownership. In some cases, women in this sample could not have home ownership as a foreseeable goal. The variation in how close low income women were to obtaining homeownership ---found both in the full sample and in the highlighted, subsampled narratives - should encourage us to question whether or not homeownership should be a goal for low income women and their families, given the complicated realities they experience. I argue that there is a need to evaluate the goals of FSS programs as a result. Specifically, evaluation of FSS programs should examine the needs of low income mothers who experience multiple and intersecting barriers to achieving self-sufficiency, as this study highlights. Low income women and their families may require additional resources to be successful in obtaining their self-sufficiency goals. For example, it may be helpful for low income women striving for homeownership to have access to a community-based support center that provides child care so women can focus on clearing their barriers to homeownership without having to worry about arranging childcare before attending financial classes, going to a job interviews, or taking on additional paid work. Low income women in FSS programs may also need additional help with transportation or networking for paid work opportunities once they receive necessary education and training. According to women in my sample, basic barriers to self-sufficiency and homeownership are still blocking the current successes of women enrolled in FSS programs. Perhaps we need to revise the resources and support services that FSS currently offer.

In addition, most African Americans and other minorities have not had the opportunity to benefit from generations of wealth accumulated through equity, putting them at a disadvantage (DeZube, 2006). Furthermore, minorities continue to have drawbacks as their mortgage applications continue to be rejected at a much higher rate than white applicants (Collins \& Dylla, 2001). Institutional discrimination has real consequences for low income women of color and their families. The TMHA escrow program could benefit these women, especially considering the fact that current literature shows that female-headed households have greater difficulty saving money than other types of households (Collins, 2002; Engle, 2013). Lack of participation in this escrow program and other saving incentive programs should be explored further in future research. Entry requirements for these savings programs should also be evaluated, to insure that a wide range of low income individuals have a chance to think about ways to save.

In addition, although transportation barriers are documented by existing studies related to the economic self-sufficiency of low income women (Hays, 2003; Newman \& Massengill, 2006; MacDonald, 2008); existing studies fail to show the complexities of low income women and their families' realities. In each of the six women's narratives presented for this analysis, there is evidence of hardship caused by transportation issues. The extent to which low income women and their families experience transportation issues is dependent upon where they live, the size of their town or city and where they reside within that city or town. Therefore, future studies must examine transportation as a complex, multi-level barrier to understand it in a more comprehensive way. 
Finally, although existing literature discusses barriers that low income women and their families face, the complex, multi-level, and intersecting nature of these barriers is not discussed widely enough. In order to enable low income families' journeys toward economic self-sufficiency and homeownership, we must pay attention to the intersecting and intertwined nature of these barriers. The situations of women and their families in this study and the barriers they face are like mathematical equations. Examining each woman's equation requires that we look not only at how many barriers they face and how they are connected, but also the weights and types of barriers they face. By studying barriers to selfsufficiency and homeownership in more complex and critical ways, we can better understand why some women begin to succeed and reach their goals while others do not.

The FSS program is designed to help low income families achieve this goal. It is clear from the data collected in this study that low income women and their families are trying to achieve their goals of economic self-sufficiency and homeownership. Unfortunately, the low income women in this study highlight more barriers than successes in reaching their goals. For now, the American Dream remains unattainable for the vast majority of interviewees. Future studies on low income women, families, economic self-sufficiency and homeownership should consider the following questions: Why do some low income families pursue homeownership instead of renting? What does homeownership mean for a family, especially for one who is having trouble making ends meet? Should government programs like the FSS program promote homeownership to low income families? Answers to these questions could better assist policymakers and social service administrators in the allocation of the appropriate funds and resources in efforts to help low income women and their families obtain their selfsufficiency goals and homeownership.

\section{Acknowledgements}

The author thanks Heather Laube, Barbara Chesney and anonymous reviewers for their helpful suggestions and comments concerning this manuscript.

\section{Bibliography}

Arnold, C. (2012). After the housing bust, revisiting homeownership. NPR, June 4, 2012. Retrieved from http://www.npr.org/2012/06/04/154160951/afterthe-housing-revisting-homeownership.

Blaauboer, M. (2010). Family background, individual resources and the homeownership of couples and singles. Housing Studies, 25(4), 441-461.

Bloomberg News. (2013). American dream slipping as homeownership at 18-year low. Bloomberg News, August 5, 2013.

Bogdon, A. (1999). What can we learn from previous housing-based selfsufficiency programs? In The home front: Implications of welfare reform and housing policy, edited by Sandra J. Newman. Washington, D.C.: The Urban Institute Press. 
Coates, D. (2013). America's half-forgotten housing crisis. Huffington Post, May 6, 2013. Retrieved from http://www.huffingtonpost.com/davidcoates/americas-half-forgotten-h_b_3222626.html.

Collins, M. \& Dylla, D. (2001). Mind the gap: Issues in overcoming the information, income, wealth, and supply gaps facing potential buyers of affordable homes. The LISC Center for Home Ownership.

Collins, M. (2002). Pursuing the American dream: Homeownership and the role of federal housing Policy. Washington, D.C.: Millennial Housing Commission.

Creswell, J. (1998). Qualitative inquiry and research design: Choosing among five traditions. Thousand Oaks, CA: Sage Publications.

Davis, K. (2008). Intersectionality as a buzzword: A sociology of science perspective on what makes a feminist theory successful. Feminist Theory, 9, 67-85.

Denis, A. (2008). Review essay: Intersectional analysis: A contribution of feminism to sociology. International Sociology, 23, 677-693.

DeZube, D. (2006). Locked out? Affordability has hit crisis proportions in many parts of the country. Who's being locked out, and is there a fix? Mortgage Banking, 67(1), 50-60.

Edin, K. \& Lein, L. (1997). Making ends meet. New York, NY: Russell Sage Foundation.

Ehrenreich, B. (2001). Nickel and dimed: On (not) getting by in America. New York, NY: Henry Holt \& Company.

Engle, J. (2013). Promoting the general welfare: Legal reform to lift women and children in the United States out of poverty. The Journal of Gender, Race \& Justice, 16 (1), 1-46.

Ficke, R. \& Piesse, A. (2004). Evaluation of the Family Self-Sufficiency Program: Retrospective analysis, 1996 to 2000. U.S. Department of Housing and Urban Development.

Garriga, C., Gavin, W., \& Schlagenhauf, D. (2006). Recent trends in homeownership. Federal Reserve Bank of St. Louis Review, 88 (5), 397411.

Gillis, C. L., Lee, K. A., Gutierrez, Y., Taylor, D., Beyene, Y., Neuhaus, J., Murrell, N. (2001). Recruitment and retention of healthy minority women in community-based longitudinal research. Journal of Women's Health \& Gender-Based Medicine, 10 (1), 77-85.

Haurin, D. (2013). The relationship of homeownership, house prices, and child well-being. Cityscape, 15 (2), 227-230.

Hays, S. (2003). Flat broke with children: Women in the age of welfare reform. New York, NY: Oxford University Press.

Heavens, A. (2006, December 21). Women still face bias in the mortgage market. Realty Times. Retrieved from http://www.orovalleyrealestate.realtytimes.com/consumeradvice/mortgage advice1/item/7647-20061221_womenbias.

Hill Collins, P. (1990). Black feminist thought: Knowledge, consciousness and the politics of empowerment. Boston, MA: Unwin Hyman. 
Lichtenwalter, S, Koeske, G. \& Sales, E. (2006). Examining transportation and employment outcomes: Evidence for moving beyond the bus pass. Journal of Poverty, 10 (1), 93-115.

Lindhorst Everhardt, S. (2009). Experiencing gender, race, and class in real life: How low income women of color strive for economic self-sufficiency and homeownership. Advances in Gender Research, 14, 189-212.

MacDonald, C. (2008). Life without father: Single mothers in the new America. Qualitative Sociology, 31, 89-94.

Martin, L. (2010). Non-married women and black ethnicity: An analysis of the likelihood of homeownership. The Western Journal of Black Studies, 34 (3), 325-336.

Newman, K. \& Massengill, R. P. (2006). The texture of hardship: Qualitative sociology of poverty, 1995-2005. Annual Review of Sociology, 32, 423446.

Pierre, R. (2007). A case study evaluation of a community college based welfareto-work program (Unpublished Doctoral Dissertation). Morgan State University, Baltimore, Maryland.

Parker, A. \& Messina, I. (2008, August 27). Toledo's household income ranks among poorest cities. The Toledo Blade, Retrieved from http://www.toledoblade.com/local/2008/08/27/toledo-s-householdincome-ranks-among-poorest-cities.html.

Pinsoneault, L. (2006). Rethinking self-sufficiency through the shared housing experience: Shared housing among low income families (Master's Thesis). University of Wisconsin at Madison, Madison, WI.

Rohe, W. \& Watson, H. (2007). Introduction: Homeownership in American culture and public policy. In Chasing the American Dream, edited by W. Rohe and H. Watson. Ithaca, NY: Cornell University Press.

Santiago, A. \& Galster, G. (2003). Moving from public housing to homeownership: Perceived barriers to program participation and success. National Poverty Center Working Paper Series, \#03-06. Retrieved from http://www.npc.umich.edu/publications/working_papers/.

Seccombe, K, James, D., \& Battle Walters, K. (1998). "They think you ain't much of nothing": The social construction of the welfare mother. Journal of Marriage and the Family, 60 (4), 849-865.

Shlay, A. (1994). Family self-sufficiency and housing. Housing Policy Debate, 4 (3), 457-495.

Simien, E. (2007). Doing intersectionality research: From conceptual issues to practical examples. Politics and Gender, 3 (2), 264-271.

U.S. Bureau of the Census. (2007). Housing vacancies and homeownership, second quarter 2007: Table 5. Retrieved from http://www.census.gov/hhes/www/housing/hvs/qtr207/ Q207tab5.htm.

U.S. Bureau of the Census. (2013). Annual Statistics: 2012, Table 17: Homeownership rates for the United States, by age of householder and by family status. Retrieved from http://www.census.gov/housing/hvs/data/ann12ind.html. 
U.S. Department of Housing and Urban Development. (2013). HUD Awards over $\$ 28$ million to promote self-sufficiency for public housing residents.

Retrieved from www.portal.hud.gov/hudportal/HUD?src=/press/press_releases_media_ad visories/2013/HUDNo.13-150.U.S.

Weber, L. (2001). Understanding race, class, gender, and sexuality: A conceptual framework. Boston, MA: McGraw-Hill.

Wilson, W. J. (1996). When work disappears: The world of the new urban poor. New York, NY: Alfred A. Knopf, Inc.

${ }^{\mathrm{i}}$ The name of this medium-sized, Midwestern city has been changed to protect study respondents.

ii Lucinda's story is discussed in the next section. 